\title{
दिगो विकास र राष्ट्रिय सुरक्षा
}

लेखसार

भौगोलिक विविधता नेपालको विलक्षण विशेषता र सुन्दर पक्ष हो। यहि विविधता विविध समयमा दिगो विकास र राष्ट्रको सुरक्षामा चुनौती बनेर उभिएको पाइन्छ। वर्तमान समयमा राष्ट्रिय सुरक्षालाई व्यवस्थित बनाउने आधार बनेको छ नेपालको दिगो विकास। देशभित्र गरिने विकासका कामहरु दिगो नहुन्जेलसम्म देशवासी र राष्ट्रिय सुरक्षाले विभिन्न किसिमका समस्याहरु सामना भोग्नुपरेको छ। देश र जनताको सुरक्षामा दिगो विकासको अग्रगामी भूमिका रहन्छ। दिगो विकाससँग जातीय विविधताको सीप, दक्षता, क्षमता र राज्यको सुरक्षा जोडिएको हुन्छ। कुनै पनि देशको जनताले राष्ट्रिय सुरक्षाको अभावमा आफू र आफ्नो समुदायका ज्ञान, उद्यम र अभ्यासलाई भरपुर रुपमा राज्य सामु दिएको देख्न सकिन्न । दिगो विकास र राष्ट्रको सुरक्षामा जनता र राष्ट्रका बिचमा सुमधुर सम्बन्ध जोडिएको हुन्छ। यस्तो स्थितिमा सैनिकनागरिक सुदृढ सम्बन्ध हेर्न पाइन्छ। दिगो विकासको अवधारणाले देशको भूगोल, जातजाति, वर्ग, लिड्ज, भाषा, संस्कृति, धर्म, रीतिरिवाज, परम्परागत ज्ञान, सीप र कलाको विकासलाई दर्साउछ। यस लेखमा राज्यमा भएको जातिय विविधिता, ज्ञान, सीप, र क्षमताका माध्यमद्धारा दिगो विकास र राष्ट्रिय सुरक्षाका बिचमा अन्तरसम्बन्ध किन, कसरी र के छ ? भन्ने बिषयलाई दर्साउन खोजिएको छं। गुणत्मक मद्धतिमा लेखिएको यस लेखमा दिगो विकासमा जनताले कसरी
अपनत्वको महसुस गई्छन ? अपनत्वले जनतालाई किन र कसरी जिम्मेवारीको बोध गराउँछ ? जनतामा एक आपसमा सकारात्मक सोच कसरी विकास गराउछ ? दिगो विकासले कसरी राष्ट्रिति र राष्ट्रिय सुरक्षालाई एक ढिक्कामा जोड्छ, ? भन्ने प्रश्नहरुका सन्दर्भमा दिगो विकासले भौतिक संरचना मात्र निर्माण हुदैन, यसले देशको ऐतिहासिक, सामाजिक, आर्थिक, साँस्कृतिक अवस्थालाई समेत बलियो बनाउछ। दिगो विकासले राष्ट्रिय सुरक्षामा महत्वपूर्ण भूमिका खेल्दै देशलाई समृद्ध र सुरक्षित बनाउँछ भन्ने निष्कर्ष यस लेखमा निकालिएको छ।

शब्दकुजी: दिगोविकास, राष्ट्रियता, सकारात्मक सोच, प्राकृतिक सम्पदा, विविधता ।

परिचय

नेपाल भौगोलिक, जातीय, भाषिक तथा धार्मिक विविधता र विशेषता भएको सुन्दर देश हो। यहाँको विकासमा 'दिगो विकास' समसामयिक विकास अभियानको एक प्रमुख कार्यसूचीको रुपमा देखापरेको छ। वातावरण र आर्थिक विकासका बिच पारस्परिक सम्बन्ध हुनुपर्ने धारणाका साथ दिगो विकासको अवधारणालाई अघि सारिएको थियो। विकासको दयारा फराकिलो हुदै गएपछि दिगो विकासले वातावरण, आर्थिक विकास, सुरक्षा, सामाजिक न्याय र मानवीय कल्याणलाई समयसंगै आफूमा समाहित गर्दे गयो। वर्तमानमा यही दिगो विकासको चर्चा गर्दा सामाजिक, 
साँस्कृतिक, मानवीय, आर्थिक, राजनैतिक र नैतिक जस्ता विषयलाई पनि एक साथ जोड दिनुपर्ने माग उठ्न थालेको छ। यी विषयहरुलाई विकासका लागि बनाइने विभिन्न योजनाहरुमा पनि स्थान दिन थालिएको छ। यसलाई एक देशको सीमाभित्र मात्र राखिने विषय होइन पनि भन्ने गरिन्छ। त्यसैले यसको चर्चा विश्वभरि नै हुने गरेको छ। अन्तर्राष्ट्रियस्तरमा सन् १९७० को दशकदेखि नै दिगो विकासका लागि नीतिगत, संस्थागत, कानुनी र व्यवहारिक प्रयासहरु हुन थालेका छन्। यसमा संयुक्त राष्ट्रसंघको विशेष भूमिका रहेको छ। अहिलेको समयमा विश्वव्यापीकरणको अवधारणाले त दिगो विकासको विषयलाई अरु विस्तार गराउन सहयोग पुच्याएको छ।

दिगो विकास अर्थात् Sustainable Development पदावलीको प्रयोग पहिलो पटक सन् १९७२ को Cocoyoc Declration मा गरिएको हो। त्यस घोषणपत्रमा वातावरण र विकासका बिच सम्बन्ध हुनुपर्ने कुरामा जोड दिइएको थियो। सुरुवाती चरणमा दिगो विषयलाई वातावरणसँग मात्र नजिक राखेर परिभाषित गरे पनि वर्तमानमा यसको दायरा विस्तार भएको छ। कुनै पनि राष्ट्रका लागि आवश्यक पर्ने सबै किसिमका विकास दिगो विकासको दायराभित्र समेटिएको छ। तर यसको मूल उद्देश्य भनेको आर्थिक विकास हासिल गर्ने क्रममा प्राकृतिक साधन स्रोतमा विचार पुच्याउनु नै हो । यसका लागि देशभित्र रहेका भौगोलिक, सामाजिक, साँस्कृतिक, मानवीय, नैतिक आदि आयामको सहायता चाहिन्छ। दिगो विकासको सर्वसम्मत परिभाषा कहीं पनि पाइदैन। दिगो विकास भन्नाले प्राकृतिक साधनस्रोतको सावधानीपूर्वक समुचित प्रयोगबाट विकास गर्ने, विकास गर्दा स्थानीय सीप, ज्ञान, विज्ञान र कलाको प्रयोग गरी विकासको दीर्घकालीन दृष्टिकोण लिने, देशको भू-बनोट, वातावरण र अर्थतन्त्रले धान्न सकिने किसिमको विकास गर्ने तथा आज गरिने विकासले भावी पुस्ताका लागि समस्या उत्पन्न हुन नदिने जस्ता विषयहरुलाई आत्मसात गरेको पाइन्छ। ब्रुण्टल्याण्ड आयोगको मान्यता अनुसार भविष्यको
पिढीको आवश्यकतामा पूरा गर्न कुनै बाधा नपुग्ने गरी वर्तमान विकासको गुणस्तर वृद्धि गर्ने गरी गरिएको विकास नै दिगो विकास हो। यस सम्बन्धमा व्यक्त गरिएका केही विचारहरुले अभै यसको अवधारणलाई स्पष्ट पारेका छन्:

- वातावणको वर्तमान गुणस्तरलाई वृद्धि गर्ने वा सो हनसकेमा कम्तिमा वातावरणप्रति तटस्थ रहने विकास तथा आर्थिक वृद्धिको स्तर नै दिगो विकास हो ।

- भगोलको वहन गर्ने क्षमतामा कुनै असर नपर्ने गरी गरिएको विकास: दिगो विकास हो।

- प्राकृतिक स्रोत साधनको दिगो व्यवस्थापन र सोबाट प्राप्त लाभको देशभित्र रहेका क्षेत्र, जाति, र समुदायमा न्यायिक वितरण नै दिगो विकास हो ।

- दिगो विकास भन्नाले प्राकृतिक स्रोत साधनको उत्पादनशील एवं प्राकृतिक गुणस्तरलाई ह्रास नगर्ने, आफैमा धान्न सक्ने, अविच्छिन्न विकास प्रक्रिया हो, जसले वर्तमान र भविष्यको पुस्ताको प्रत्येक व्यक्तिको न्यूनतम जीवनयापन गर्न पाउने नैसर्गिक अधिकारलाई संरक्षण गर्दछ,।

दिगो विकासको अवधारणाको आधारशीलाका रुपमा मूलतः वातावरणसंग सम्बन्धित विषयलाई नै महत्व दिएको छ। हरेक आर्थिक क्रियाकलाप र सुरक्षाको अन्तिम आधार भनेको प्राकृतिक संसाधन हो। हरेक देशको आर्थिक गतिविधि अन्तमा आएर प्राकृतिक साधनमै निर्भर हुन्छ। प्राकृतिक साधनको आधार निश्चित र सीमित हुन्छ। प्राकृतिक साधनको अनुचित दोहन र असावधानीपूर्वक प्रयोग भएमा भविष्यको आवश्यकता र उत्पादनमा नकारात्मक प्रभाव पछ। तर नैतिक, सामाजिक, साँस्कृतिक, भाषिक, आर्थिक र राजनैतिक रुपमा सन्तुलित विकासबिना देशको दिगो र समग्र विकास अगाडि बढ्न सक्दैन भन्ने परिधिभित्र रहेर दिगो विकासको अवधारणालाई बुक्ने र बुकाउने गरिएको छ। 


\section{दिगो विकास र राष्ट्रिय सुरक्षा बिच सम्बन्ध}

दिगो विकास र राष्ट्रिय सुरक्षा बिच अन्योन्याश्रित सम्बन्ध रहेको हुन्छ। राज्य वा सरकारले आफनो राज्यशक्ति प्रयोग गर्दे राजनैतिक, अर्थिक, सामाजिक तथा सैन्य क्षेत्र र शक्तिको सुदुढीकरण मार्फत राज्यलाई आन्तरिक र बाह्यय चुनौतीहरुबाट मुक्त गरी मुलुकमा सुख, शान्ति र सुव्यवस्था कायम गर्ने बहुआयामिक रणनीति राष्ट्रिय सुरक्षा नीति हो। त्यस नीतिअर्त्तगत नेपालको सार्वभौमसत्ता, भौगोलिक अखण्डता, स्वधीनता, नागरिक स्वतन्त्रता, मानव अधिकार जस्ता मूल्यमान्यताहरु आत्मसात गर्दे आर्दश राज्य र सुखमय मानवजीवनको प्रत्याभति गराउनु राष्ट्रिय सुरक्षा व्यवस्थापनको उद्देश्य पनि हो। सुदृढ राजनीति, सबल कूटनीति, सबल सामाजिक सुरक्षा, सबल सैन्य शक्ति तथा मानवीय सुरक्षा राष्ट्रिय सुरक्षाका आधारभूत तत्वहरु हुन ।

नेपालको संविधान (२०७२) को प्रस्तावना, राष्ट्रिय सुरक्षा नीति, २०७३ र पन्द्रौं पन्चवर्षीय योजनाले निर्दिष्ट गरे अनुसार नेपालको बहुजातीय, बहुसांस्कृतिक, बहुभाषिक, बहुधार्मिक तथा भौगोलिक विविधतायुक्त विशेषताको परिवेशमा राष्ट्रिय एकता, सामाजिक एवं सांस्कृतिक ऐक्यबद्धता, सहष्णिता र सद्भावको संरक्षण आवश्यक छ। राष्ट्रिय सुरक्षाले भौगोलिक, सामाजिक, आर्थिक र राजनैतिक रुपमा देशको पर्ण सुरक्षालाई बुकाउँछ। हरेक देशले आफना आधारभूत मल्य र मान्यतामा आधारित राष्ट्रिय आकांक्षा र अति महत्त्वपर्ण राष्ट्रिय हितका विषयहरुको पहिचान गरेको हुन्छ। प्राकृतिक स्रोतहरुको अति र अव्यवस्थित दोहन, अनियत्त्रित जनसड्ख्या वृद्धि, महामारीको विस्तार, खाद्यान्न असुरक्षा एवं स्वच्छ पिउने पानीको अभाव जस्ता समस्या देखापरिरहेका छन्। अन्तर्राष्ट्रय, क्षेत्रीय र स्थानीय दून्द्ध तथा अस्थिरताको कारण आज समस्या उत्पन्न हुने गरेको छ। स्रोतहरुमा सीमित व्यक्ति तथा राष्ट्रहुको बढ़दो आधिपत्यले असमानता सिर्जना गरी दून्द्ध उत्पन्न हुने गरेको छ। यसले गर्दा राष्ट्रिय र
अन्तर्राष्ट्रिय सुरक्षा वातावरण जटिल तथा चुनौतीपर्ण बन्दे गएको र परिवर्तित भइरहेको परिस्थितिमा राष्ट्रिय सुरक्षा सुदृढ हुनु अत्यावश्यक छ।

नेपालको दिगो विकास र सुरक्षा बहुआयामिक विषय भएकाले यसले मुलकको सार्वभौमिकता, राष्ट्रिय अखण्डता, भौतिक, सामाजिक, आर्थिक, सांस्कृतिक र मानवीय पक्षलाई समेट्दछ। यस अन्तर्गत सार्वजनिक र निजी मूल्य-मान्यताहरु, राष्ट्रिय सम्मान र गौरव, जिडधन एवं सामाजिक-सांस्कृतिक मूल्यको सुरक्षा र संरक्षण पनि पर्दछ् । वातावरण, सुशासन, विकास र मानव अधिकारको पक्षलाई पनि राष्ट्रिय सुरक्षा नीतिले समेट्दछ। यी क्षेत्रमा उत्पन्न हुने समस्या र जोखिमलाई न्यून गर्दे समग्रमा राष्ट्रका अति महत्वपर्ण राष्ट्रिय हितहरुको रक्षा र सुरक्षा नीतिको कार्यान्वयनद्वारा गरिन्छ। यसअर्त्तगत सैनिक सुरक्षा समेतका सुरक्षा प्राथमिकता र उपाय लगायतका पक्ष र आयामहरु पर्दछन् ।

\section{दिगो विकास र राष्ट्रिय सुरक्षाका उद्देश्यहरु}

दिगो विकास र राष्ट्रिय सुरक्षाका मूल उद्देश्यहरु वातावरण, सामाजिक, आर्थिक विकास बिच समन्वय कायम गरी देश र जनताको कल्याण गर्नु हो। यसका अन्य उद्देश्यहरुमा

(क) वातावरणको प्रभावकारी संरक्षण गर्नु,

(ख) प्राकृतिक स्रोत-साधनको न्यायोचित बाँडफाँड गरी सावधानीपर्वक प्रयोग गर्नु,

(ग) दिगो आर्थिक वृद्धि हासिल गरी नागरिकलाई आन्तरिक र बाह्य सुरक्षाको प्रत्याभति गराउनु,

(घ) सामाजिक सद्भाव कायम गर्ने र सबै जाति, समुदाय बिच राष्ट्रियताको भावना जागृत गराउनु,

(ङ) सामाजिक, सांस्कृतिक, भाषिक तथा स्थानीय ज्ञान, सीप र कलाको विकास गर्नु र

(च) सामाजमा नैतिक धरातललाई बलियो बनाई एक अर्काप्रति जिम्मेवार बनाउनु। 


\section{दिगो विकास र राष्ट्रिय सुरक्षाका आयामहरु}

दिगो विकासको प्रारम्भिक चरणमा वातावरण र विकासको आयामका आधारमा हेर्ने गरिन्य्यो भने सुरक्षालाई पनि बाह्य र आन्तरिक आक्रमणबाट देश र जनतालाई सुरक्षित राख्ने कुरालाई बुकिन्थ्यो। पछि आएर वातावरण संरक्षण, आर्थिक र सामाजिक विकास, राष्ट्रियता मजबुत पार्ने तत्व जातीय, भाषिक, धार्मिक, राजनैतिक दून्द्धहरुको यथोचित समाधान, शान्ति तथा सुव्यवस्था मार्फत् सार्वभौमसत्ताको रक्षा, आधारभूत आवश्यकताको व्यवस्थापन, स्रोत-साधनको पर्याप्त र आवश्यकतामा आधारित परिचालनको आधार स्तम्भका रुपमा प्रस्तुत गर्न थालियो। अहिलेको २१ औ शताब्दीमा दिगो विकास र राष्ट्रिय सुरक्ष भन्नाले समग्र राष्ट्रिय विकासका लागि एक साथ गरिने प्रयास भनेर बुक्रु पर्दछ। आजको समयमा दिगो विकास र राष्ट्रिय सुरक्षाका आयाममा राजनैतिक, वातावरणीय, सामाजिक, सांस्कृतिक, मानवीय र नैतिक पक्षहरु पनि समावेश भएको पाइन्छ। यी विभिन्न आयामहरुलाई निम्न अनुसार बुक्न सकिन्छ :

\section{(क) वातावरणीय आयाम}

वातावरणीय आयाम दिगो विकास र सुरक्षाको प्रमुख आयाम हो। दिगो विकासको अवधारणाको आधार नै प्राकृतिक सम्पत्तिको प्रयोग गर्दा ध्यान दिनुपर्ने विषय हो। यसभित्र पर्ने मुख्य विषयहरु हुन् : प्राकृतिक संसाधनको दिगो उपयोग गर्ने, प्राकृति निधि र सम्पत्तिको गुणस्तर वृद्धि र जगेर्ना, प्रकृतिबाट उत्पन्न हुने फोहोर, प्रदूषण आदिलाई प्रकृतिले पुन: प्रयोग र प्रशोधन गर्ने क्षमताको अभिवृद्धि वा त्यस्तो क्षमताको ह्रास आउन नदिने, उत्पन्न समस्यालार्य स्थानीय ज्ञान र सिपको प्रयोग गरेर समाधान गर्न सकिन्छ भनेर सावधानी राखे, सचेत हुने, वातावरण संरक्षणको लागि नीतिगत, कानुनी र संसथागत व्यवस्था आदि हुन् ।

\section{(ख) आर्थिक आयाम}

देशमा आर्थिक विकासको लक्ष्य हासिल गर्न वातावरणीय पक्षमा ध्यान दिनुपर्ने आग्रहका साथ दिगो विकासको अवधारणा अघि सारिएको छ। दिगो विकास गर्न स्वास्थ्य र समष्टिगत आर्थिक व्यवस्थापन गर्ने, गरिबी निवारण उन्मुख आर्थिक वृद्धि हासिल गर्ने, दिगो उत्पादन वृद्धि हासिल गर्ने, आर्थिक क्षेत्रको विकासका सन्दर्भमा सरकारको उपयुक्त भूमिका विकास गर्ने, हरित लेखापलन पद्धतिको विकास गर्ने र समानुपातिक वितरणमा ध्यान दिनुपर्ने जस्ता विषयमा जोड दिने गरिएको छ। त्यति बेला दिगो विकास शब्दको प्रयोग नगरे पनि लिच्छिविकालीन शासन व्यवस्थामा यस पद्धतिको प्रयोग भएको पाइन्छ। यही दिगो विकास र राष्ट्रिय सुरक्षाको अवधारणा अनुसरण गरेर अगाडि बढेकाले नेपालको इतिहासमा लिच्छिविकाललाई स्वर्णकाल भनेर चित्रण गरिएको छ। त्यस्तै गरेर आधुनिक नेपालका निर्माता श्री $y$ बडामहाराजाधिराज पथथ्वीनारायण शाहले आफनो जीवनको धेरै समय राज्य विस्तारमा दिए पनि आफनो "दिव्य उपदेश" मा दिगो विकास र राष्ट्रिय सुरक्षाको विषयलाई स्पष्ट यसरी पारेका छन् :

देस का महाजनलाई गोड प्रसाह देषी उभो आउन नदिनु, देशका महाजनहरु हाम्रा मुलुकमा आया भन्या दुनिाजां कंगाल गरि छाडद्छन्। हामीले च्यागापागालाई तिन सहर नेपाल र नौलाष किरायत र हिन्दुपतिको राज अर्ज्यथ्येज। देसका कपरा लगाउनलाई मह्नाई गरिदिनु। आफ्ना देसका कपरा बन्न जान्यालाई नमना देषाई सघाउनु र बन्न लाउनु र यस्व भया नगद देस जादैन ।आफ़ना देसको जिनीस जरिबुटि देस लैजानु र नगद बैचनु, नगद बैचि राषनु र प्रजा मोटा भया दर्बार बलियो रहन्छ, राजाका भंडार भन्याका रैतानहरु हुन्। मेरा साना दषले आज्ज्याको मुलुक होइन, सबै जातको फुलबारि हो, सबैलाई चेतना भया। यो फुलबारि हो। सबेलाई चेतना भया, यो फुलबारिको छोटो बडा चारै जात छत्तिसै बर्नले सम्भार गर्नु पई। 


\section{(ग) सामाजिक आयाम}

दिगो विकास र राष्ट्रिय सुरक्षाको लक्ष्य प्राप्त गर्न समग्र सामाजिक विकासको पक्षलाई पनि उत्तिकै महत्व दिनुपछ। यसका लागि समानता मात्र नभएर समतामूलक वितरण प्रणालीको विकास गर्ने, सामाजिक सेवाहरुको गुणस्तरीय विस्तार गर्ने, लैंगिक समताको विकास गर्ने, राष्ट्रले धान्न सक्ने स्तरको जनसङ्ख्या कायम गर्ने, समाजप्रति उत्तरदायी नागरिक र व्यवस्थाको विकास गर्ने, सामाजिक सद्भाव गर्ने तथा यसलाई विथोल्ने वा कमजोर पार्ने तत्वको समयमा नै पहिचान गरी स्थानीय मल्यमान्यता, ज्ञानको आधारमा समाधानको उपाय निकाल्ने जस्ता कामहरु गर्नुपर्दछ।

\section{(घ) मानवीय आयाम}

दिगो विकास र राष्ट्रिय सुरक्षालाई गतिशील बनाउने तत्व नै मानवीय आयाम हो। यो मुख्यतः मानव कल्याणका विषयमा समतामूलक तथा सकारात्मक विभेदको व्यवस्था गर्ने अवधारणामा आधारित छ। मानव जातिका आधारभूत आवश्यकता परिपूर्ति गर्ने, आधारभूत मानव अधिकारको संरक्षण र सम्बर्द्धन गर्ने जस्ता पक्षहरु यस आयामअर्न्तगत पर्दछ् ।

\section{(ङ) राजनैतिक आयाम}

विश्व परिवेशमा नै विगतमा राजनैतिक व्यवस्था जस्तोसुकै भए पनि देशको आर्थिक विकास गर्न सकिन्छ, भन्ने मान्यता थियो। यही मान्यता अनुरुप सन् १९५० र ६० को दशकमा एकदलीय र तानाशाही व्यवस्था जसले सरकारको एकल भमिकालार्य आधार मान्थ्यो, यस्ता व्यवस्थाका माध्यमबाट देशको समग्र विकास गर्ने प्रयासहरु भए। केही अपवादहरुलाई छोडेर तानाशाही राजनैतिक ज्यवस्था भएका देशहरुले देशको समग्र विकास गर्न सकेनन्। त्यसैले सन् १९७० को दशकदेखि नै बहुदलीय प्रजातात्त्रिक व्यवस्थाका माध्यमबाट मात्र देशलाई दीर्घकालीन प्रभाव पार्न सक्ने विकास गर्न सकिन्छ भन्ने धारणा विकसित हुादै गयो। यसको लागि राजनैतिक रुपमा प्रजातत्त्रिकरण, समानुपातिक प्रतिनिधित्वको व्यवस्था, स्थानीय स्वायत्त शासनमा
जोड दिने जस्ता मान्यताहरु विकसित हुँदै गए । त्यसैले दिगो विकास र राष्ट्रिय सुरक्षाको लक्ष्य हासिल गर्न प्रजातात्तिक राजनैतिक व्यवस्थाको आवश्यकता पर्दछ, भन्ने मान्यताको विकास भएको हो। यस व्यवस्थामा जनता आफैले आफूमाथि शासन गर्ने भएकाले दिगो विकास र राष्ट्रिय सुरक्षाको सवालमा सबै भूगोल, जाति, धर्म, भाषा, संस्कृति, मूल्यमान्यता, ज्ञान र सिपलाई मूल प्रवाहमा आउन सक्छ़् ।

\section{(च) नैतिक आयाम}

दिगो विकास र राष्ट्रिय सुरक्षालाई सकारात्मक मोडमा पुय्याउने विभिन्न आयाम मध्ये नैतिक आयाम एक हो। दिगो विकास र राष्ट्रिय सुरक्षाका लागि संस्थागत, नीतिगत, कानुनी आधारहरु सिर्जना गरेर मात्र पुग्दैन, देशको प्रत्येक भूगोलमा बस्ने विभिन्न जातजाति, भाषिक समुदाय, धर्मावलम्बी, पेसा र व्यवसय भएका नागरिकहरुलाई नैतिक रुपमा जिम्मेवार बनाउनुपछ। नैतिक रुपमा जिम्मेवारी बोध भएका नागरिकहरुको समूहबाट मात्र दिगो विकास र राष्ट्रिय सुरक्षाको लक्ष्य प्राप्त गर्न सकिन्छ ।

\section{नेपालमा दिगो विकास र सुरक्षाका लागि भएका प्रयासहरु}

नेपालमा दिगो विकासको थालनी विगतमा कहिलेदेखि भयो भन्ने तथ्य किटानीका साथ कतै उल्लेख नभए पनि नेपालका लिच्छविकालीन शासक वा राजाहरुले यस अवधारणाको अनुसरण गरेका थिए। लिच्छवीकालिन इतिहासबाट स्पष्ट हुन आउछ। त्यसपछिका राजाहरुले पनि राज्य सञ्चालनमा यसलाई महत्व दिएको पाइन्छ। पछि, आधुनिक नेपालका निर्माता श्री $y$ पृथ्वीनारायण शाहले स्थानीय स्रोत, साधनको समुचित प्रयोगमा विशेष ध्यान दिएका र आफ़ना सहयात्रीहरुलाई यसका बारेमा अवगत गराएका कुरा उनको जिवनी र "दिव्य उपेदश" बाट थाहा पाउन सकिन्छ। उदाहरणका लागि वनजड्रलको संरक्षण गर्ने, एउटा रुख काटेपछि, दुईवटा रोप्नु पर्ने चलन, नदीमा माछा मार्ने परिपाटी कम 
गर्ने, असारमा माछा मार्दा गर्भिणी माछा छाडिदिने, समुदायमा कुनै काम गर्दा समुदायका सबै मानिस एक जुट भएर गर्नुपर्ने, सबैको सहमति हुनुपर्ने आदि विषयहरु नेपालको विकासमा धेरे अगाडिदेखि नै समावेश हुंदै आएका छन्। वातावरण संरक्षणका लागि नीतिगत रुपमा योजनामा उल्लेख भने छैटौं योजनादेखि भएको हो। त्यस योजनामा पहिलो पटक वातावरण तथा भूउपयोग नीतिलाई राष्ट्रियस्तरको नीतिका रुपमा समावेश भयो। सन् १६दर मा श्री $y$ महेन्द्र प्रकृति संरक्षण कोषको स्थापना भयो। यसले विकास र वातावरणका बिच सम्बन्ध र समन्वय कायम गर्नमा भूमिका खेल्दै आएको छ। सरकारले नेपाल वातावरणीय नीति तथा कार्ययोजना जारी गरी लागु गरेको छ। उक्त कार्ययोजनामा अन्य कुराका अतिरिक्त प्राकृतिक स्रोत साधनको दिगो व्यवस्थापन गर्ने, जनसंख्या, स्वास्थ्य र गरिबी निवारणसम्बन्धी कार्यक्रमहरु सन्चालन गर्ने, राष्ट्रिय सम्पदाको संरक्षण गर्ने, विकासजन्य वातावरणीय असर घटाउने जस्ता नीतिहरुको व्यवस्था गरिएको छ।

नेपालमा योजनाबद्ध विकासमा र $द$ औ योजनादेखि दिगो विकास भनेर किटानीका साथ औपचारिक प्रयास सुरु भएको थियो। यस योजनामा तिन प्रमुख उद्देश्यमध्ये एक उद्देश्य दिगो आर्थिक विकास हासिल गर्ने रहेको थियो। त्यस योजनामा :

(क) गाँउदेखि नै धान्न सकिने विकास प्रक्रिया अँगाल्ने,

(ख) वार्षिक बजेटको ७० प्रतिशत रकम गाँउको विकासमा प्रयोग गर्ने,

(ग) वातावरण र विकास बिच सामझ्जस्यता ल्याउने,

(घ) सन्तुलित विकास गर्ने जस्ता विषयमा विशेष जोड दिइएको थियो ।

यसका साथै त्यस योजनामा उल्लेख भएका अन्य नीतिगत तथा कार्यक्रमगत विषयहरुमा समेत दिगो विकास हासिल गर्ने कुरामा जोड दिइएको थियो ।
त्यसपछि विकास योजनाहरु कमशः ९ औं देखि १४ औं सम्म योजनामा समसेत दिगो विकासको अवधारणालाई आत्मसात् गरिएको छ। दिगो विकास हासिल गर्न विभिन्न नीतिगत र कार्यक्रमगत विषयहरुलाई विशेष महत्वका साथ अगाडि सारिएको छा गरिबी निवारण, रोजगारी सिर्जना, प्राकृतिक तथा सास्कृतिक सम्पदाको संरषण, वातावरण संरक्षण, माहिला सशक्तीकरण, विभिन्न पछाडी पररिरहेका वर्ग र क्षेत्रका लागि विशेष कार्यक्रमहरु सन्चालन जस्ता विषयमा जोड दिई स्थानीयलाई पनि सहभागी गराउँदै आएको छ। यसका साथै सुशासन कायम गर्ने, स्थानीय स्वायत्त शासनको विकास गर्ने, दिगो अर्थिक विकास हासिल गर्ने नीतिहरु अवलम्बन गरिएको छ। विभिन्नसंस्थागत र कानुनी व्यवस्थाका माध्यमबाट दिगो विकास हासिल गर्ने प्रयासहरु भइरहेका छन्। वातावरण संरक्षण परिषद, जनसंख्या तथा वातावरण मत्त्रालय, विभिन्न मत्त्रालय जस्तै: रक्षा मन्त्रालय अन्तर्गतका नेपाली सेनाबाट हुने विकास निर्माणका कामहरु तथा वातावरणसम्बन्धी एकाइहरु र राष्ट्रिय योजना आयोगअर्त्तगत वातावरण महाशाखा यसका उदाहरण हुन्। यसरी नै वातावरण संरक्षणमा सम्बन्धमा नेपाल अधिराज्यको संविधान, २०४७ को "राज्यका निर्देशक सिद्धान्त तथा नीतिहरु" अर्त्तगत वातावरण संरक्षणमा जोड दिने व्यवस्था गरिएको थियो। नेपालको अन्तरिम संविधान २०६३ को भाग-३, मौलिक हक र कर्तव्य अर्त्तगत पनि दिगोविकाससम्बन्धी अधिकार र कर्तव्यको विषय समावेश गरिएको थियो। यहि संविधानको भाग- $\checkmark$, राज्यका निर्देशक सिद्धान्त, नीति तथा दायित्व अर्त्तगत दिगो विकास, वातावरण र सुरक्षा सम्बन्धी व्यवस्था गरिएको छ। यसरी नै नेपालको संविधान (२०७२) को भाग-३, मौलिक हक र कर्तव्य अर्त्तगत पनि दिगोविकाससम्बन्धी अधिकार र कर्तव्य विषय समावेश गरिएको छ। यही संविधानको भाग-४, राज्यका निर्देशक सिद्धान्त, नीति तथा दायित्वअर्त्तगत दिगो विकास, वातावरण र सुरक्षासम्बन्धी व्यवस्था गरिएको छ।

वर्तमान समयमा राष्ट्रिय सुरक्षा सबैभन्दा महत्वपूर्ण विषय हो। इतिहासमा वर्णन गरिए जस्तो बलियो 
सेना, प्रशस्त हातहतियार, दुर्भेद्य किल्ला, अनुशासितमिहिनेती नागरिक, दक्ष र कुटनीतिमा निपुण गुप्तचर र दूरदर्शी तथा चतुर शासक आदिलाई राष्ट्रिय सुरक्षाका आवश्यक आधारका रुपमा लिइन्थ्यो, तर अहिले यस्तो छैन। राष्ट्रिय सुरक्षाका विषयवस्तुमा पनि धेरै परिवर्तन भएको छा दिगो विकास र राष्ट्रिय सुरक्षाको विषय निरन्तर चलिरहने प्रक्रिया पनि हो ।

नेपालको राष्ट्रिय सुरक्षाका सन्दर्भमा आधुनिक नेपालका निर्माता श्री $y$ बडामहाराजधिराज पृथ्वीनारायण शाहको 'दिव्य-उपदेश' मा व्यक्त भएका अमुल्य विचार नै दूरदर्शी छन्। 'दिव्य-उपदेश' मा उल्लिखित वाक्यहरुमा लिखित : प्रजा मोटा भया दर्बार बलियो रहन्छ, राजाका भंडार भन्याका रैतानहरु हुन। र यो राजे दुई ढुंगाको बीचको तरुल जस्तै रहेछ। अर्थात् सबल जनता र बलियो आर्थिक अवस्था नै राष्ट्रिय सुरक्षाको पहिलो र विश्वासिलो आधार हो। यस धारणालाई वर्तमानको कुनै राजनीति, अर्थनीति र सुरक्षानीतिले नकार्न सक्दैन। राष्ट्रिय सुरक्षालाई दुई भागमा राखेर विश्लेषण गर्ने गरिन्छ:, आन्तरिक सुरक्षा र बाहय सुरक्षा। आन्तरिक सुरक्षाले देशभित्र शान्ति र अमन-चयनलाई बुकाउँछ। यसका लागि कानुनी राज्य सुशासन, राजनैतिक स्थिरता, सामाजिक न्याय र सद्भाव, दिगो आर्थिक विकास आदि आवश्यक पर्दछन् । दिगो आर्थिक विकासका अभावमा शान्ति सुव्यवस्था खल्बलिना साथै राष्ट्रिय सुरक्षा पनि कमजोर हुन जान्छ। दिगो आर्थिक विकासले शासकीय अस्थिरता, हिंसात्मक गतिविधि, अनियिन्त्रित जनआक्रोश आदिलाई कम गर्दे राष्ट्रिय सुरक्षामा सहयोग पुय्याउँछ। बाह्य सुरक्षा भन्नाले कुनै सार्वभौम सत्तासम्पन्न राष्ट्रमाथि अन्य राष्ट्रबाट हुन सक्ने हस्तक्षेप, अतिक्रमण वा आक्रमणबाट जोगाएर राख्नु हो। यसको प्रमुख आधार भनेको कुशल कटनीति नै हो भने अर्को उपाय भनेको आन्तरिक सुरक्षा बलियो हुनु र दिगो आर्थिक विकास हो । लिच्छिविकाल उदाहरणका लागि राजकुमारी भुकुटीको बिहे तिब्बतका सम्राटसँग गरिदिएर, मल्लकालमा : कलाकार अरनिकोलाई चीन पठाएर र आधुनिककालमा : बिहेवारी, मितेरी साइनो र व्यापारिक सम्बन्ध आदि
बढाएर, कुशल कटनीतिके कारणले बाह्य हस्तक्षेबाट देशलाई सुरक्षित राख्न सफल भएको हो।

थोमस हब्सले सन् १६५११ मा शक्तिशाली राज्य निर्माणमा सार्वभौम सुरक्षाको अवधारणा लयाएका थिए भने इमानुअल कान्टले यस अवधारणालाई विस्तार रूपमा राजनैतिक, आर्थिक, सांस्कतिक पक्षसँग जोडेर चर्चा गरेका थिए। हुन त राष्ट्रिय सुरक्षाको अवधारणा द्वितीय विश्वयद्ध पशचात सन् $9 ९ ४ \%$ मा अमेरिकाबाट सुरु भएको हो, नेपालको सन्दर्भमा राष्ट्रिय सुरक्षालाई विशेष महत्व दिन थालिएको केही वर्ष मात्र भएको छ। इतिहासको अध्ययन गर्दा नेपालको एकीकरणपछि, पृथ्वीनारायण 'शाहको 'दिव्योपदेश' लाई नै सुरक्षा नीतिका रूपमा लिने गरिएको पाइन्छ। केही जानकार हरुका अनुसार वि.सं. २०४२ मा ल्याइएको राष्ट्रिय मूल नीतिलाई नै राष्ट्रिय सुरक्षा नीतिको संज्ञा दिएको थियो। नेपालको राष्ट्रिय सुरक्षालाई सुदृढ बनाउन नेपाल सरकारले सुरक्षा नीति २०७३, जसमा आन्तरिक तथा बाह्य सुरक्षालाई व्यवस्थापनका लागि दीर्घकालीन र अल्कालीन नीतिहरु तयार गरेको छ, र कार्यान्वयनमा ल्याएको छ। राष्ट्रिय सुरक्षा नीति २०७३ ले विभिन्न आन्तरिक तथा बाह्यय सुरक्षा चुनौतीको पहिचान गरी त्यसको समाधानका उपायहरू निकालेको छ। नेपालको आन्तरिक सुरक्षा चुनौतीका रूपमा राजनैतिक चुनौती, कानुन व्यवस्था सम्बद्ध चुनौती, सामाजिक, आर्थिक चुनौती, विपद् र प्राकृतिक स्रोतको क्षति सम्बद्ध चुनौती र अतिवाद रहेका छन्। मुलुक सछ्दीय व्यवस्थामा गइसकेको भए पनि व्यावहारिक रूपमा कार्यान्वयनकै चरणमा छ।

नेपालको संविधान-(२०७२) को धारा-४१ मा राष्ट्रिय एकता र सुरक्षासम्बन्धी नीतिलाई समेटिएको छ। यसै संविधानको भाग-२६ मा राष्ट्रिय सुरक्षासम्बन्धी व्यवस्था गरिएको छ, जसमा नेपालको स्वतन्त्रता, सार्वभौमसत्ता, भौगोलिक अखण्डता र स्वाधीनताको संरक्षण गर्ने, राष्ट्रिय सुरक्षा प्रणालीको विकास गरी शान्ति सुरक्षाको व्यवस्था गर्ने, सर्वाड़ीण मानवीय सुरक्षाको प्रत्याभति गर्ने कुरा उल्लेख गरिएको छ। यसै गरी राष्ट्रिय सुरक्षाको महत्वपर्ण विषय देशमा 
रहेका सबै सुरक्षा निकायहरूलाई राष्ट्रिय सुरक्षा नीतिका आधारमा सबल, सुदृढ, व्यावसायिक, समावेशी र जनउत्तरदायी बनाउने तथा पूर्व सैनिक, कर्मचारी, प्रहरीलगायतका पूर्व राष्ट्रसेवकहरूमा रहेको ज्ञानसीप प्रयोग गर्ने र राष्ट्रिय आवश्यकताअनुरूप नागरिकलाई राष्ट्रको सेवा गर्न तत्पर र सक्षम बनाउने कुरा उल्लेख गरिएको छ, जसको व्यावहारिक कार्यान्वयन हुन सकेको खण्डमा राष्ट्रिय सुरक्षा थप मजबुत हुन सक्छ। यसरी वर्तमान नेपालको संविधानले समेत राष्ट्रिय खतराको पूर्वमूल्याङ्कन गरी राष्ट्रिय सुरक्षाको विषयलाई संवेदनशील रूपमा उठाउन खोजको छ,

\section{दिगो विकास र राष्ट्रिय सुरक्षाका चुनौतीहरु :}

दिगो विकास र राष्ट्रिय सुरक्षाको सवालमा बहस, छलफल र गोष्ठी गर्न जति सहज छ, यसको लक्ष्य प्राप्त गर्न त्यति नै चुनौतीपूर्ण रहेको छ। राष्ट्रिय र अन्तर्राष्ट्रिय स्तरमा व्यापक प्रयासका अतिरिक्त दिगो विकास र राष्ट्रिय सुरक्षाको लक्ष्य हासिल हुन सकिरहेको छैन। यी दुबै बहुआयामिक र बहुदेशीय सरोकारका विषय भएकाले पनि यस्तो भएको हुन सक्छ। प्राकृतिक स्रोत-साधनको पहिचान, व्यवस्थापन र समुचित प्रयोगको अभाव तथा विकासप्रतिको दृढ प्रतिबद्धताको कमीले गर्दा पनि यो चुनौतीपूर्ण भएको छ। यी दुबै पक्षलाई सँगसँगै राखेर हेर्दा देहाय बमोजिमका चुनौतीहरुलाई मुख्य रुपमा उल्लेख गर्न सकिन्छ :

\section{(क) वातावरणीय जटिलता}

राज्यभित्र उपलब्ध प्राकृतिक स्रोत-साधनको संरक्षण र त्यसको सावधानीपूर्वक प्रयोग दिगो विकास र राष्ट्रिय सुरक्षाको आधार स्तम्भ हो । तर यसको असावधानीपूर्वक प्रयोगले प्राकृतिक वातावरणमा व्यापक ह्रास आएको छ। वायु प्रदूषण, शुद्ध पिउने पानीको अभाव र खाद्य असुरक्षा बढ़दै गएको छ। माटोको उर्वराशक्तिमा कमश: गिरावट आउंदै गएको छ भने वनविनाश पनि तिव्र गतिमा बढिरहेको छ। जैविक विविधता प्रतिदिन लोप हुँदै गएको छ। यस्तो अवस्थामा दिगो विकास र राष्ट्रिय सुरक्षाको लक्ष्य हासिल गर्न धेरै ने चुनौतीपूर्ण हुने देखिन्छ।

\section{(ख) बढ़दो गरिबी}

दीगो विकास र राष्ट्रिय सुरक्षाको उद्देश्य हासिल गर्नमा गरिबीको अवस्थामा सुधार हुनु अति आवश्यक मानिन्छ। तर यी दुबै विषय अलि विवादास्पद पनि छन्। दिगो विकास र राष्ट्रिय सुरक्षाद्धारा गरिबी कम गर्न सकिन्छ भन्ने एउटा धारणा रहेको छ भने अर्कातिर गरिबी निवारण गर्न सकेमा दिगो विकास र राष्ट्रिय सुरक्षाको लक्ष्यमा पुग्न सकिन्छ भन्ने मत छ। यसरी यी दुबै विषय एकअर्काका पूरक हुन भन्ने कुरामा कुने दुई मत छैन्। गरिबी घटाउने काममा तीव्रता आएको छ, तर गरिबीको रेखामुनि रहेका मानिसको संख्या भने बढ़दो ऋममा रहेको छ। यसले दिगो विकास र राष्ट्रिय सुरक्षाको लक्ष्य प्राप्तिमा चुनौती खडा गरिरहेको छ।

\section{(ग) सामाजिक विभेद र आन्तरिक द्वन्द्ध}

सामाजिक समावेशीकरण, सामाजिक सद्भाव र सामाजिक समानता तथा समता बिना देशको समग्र आर्थिक विकासलाई दिगो बनाउन सकिँदैन। अनि राष्ट्रिय सुरक्षाको प्रत्याभूति पनि गराउन सकिंदैन । नेपाल जस्तो विकासोन्मुख देशहरुमा सामाजिक विभेद, आन्तरिक दून्द्ध र असमानता जस्ता विकृतिहरुले दबदबा बढाएका छन्। यी दून्द्ध र असमानताहरुले विकासका पूर्वाधार र सुरक्षामा खर्चिनपर्ने ठूलो धनराशिको दुरुपयोग गरिरहेका छन्। वर्षेनी यसको समाधान र व्यवस्थापनमा आर्थिक र मानवीय शक्तिको अधिक उपयोग भइरहेको छा दून्दको कारण राष्ट्रिको ध्यान दिगो विकास र सुरक्षाप्रति केन्द्रित हुन सकेको छैन्। यी समस्याहरुको समाधान र व्यवस्थापन गरी दिगो विकास र राष्ट्रिय सुरक्षाको लक्ष्य हासिल गर्नु चुनौतीपूर्ण छ।

\section{(घ) आर्थिक पक्षमा बाह्य प्रभाव}

देशको विकास र सुरक्षामा आफ्नोपनको वा स्वामित्वको अहम भूमिका हुन्छ। विकासोन्मुख देशहरुमा यसको कमी अनुभुति हुने गरेको छ। नेपाल पनि आर्थिक दृष्टिकोणले धनी देशहरुको अधीनमा रहन बाध्य छ। आर्थिक उदांरीकरण, विश्वव्यापीकरण, विदेशी सहयोगमा निर्भरता जस्ता कारणहरुले विकासोन्मुख देशहरु धेरै किसिमबाट ठुलो मारमा परेका छन्। 
आफ़नो देशको परिवेशअनुरुप विकास गर्ने अवसरबाट गरिब देशहरु क्रमश: विमुख हुँदै गएका छन्। बाह्य प्रभावले भएको आर्थिक विकासले सीमित व्यक्तिको विकास भएको छ तर समुदायको अवस्था दिनप्रतिदिन खसकँदै गएको पाइएको छ। यस्तो आर्थिक परिवेशमा दिगो विकास र राष्ट्रिय सुरक्षा हासिल गर्नु विकासोन्मुख देशको लागि चुनौतीपूर्ण हुन्छ।

\section{(ङ) सुशासन अभाव}

सुशासन राष्ट्रको समग्र विकास र राष्ट्रिय सुरक्षाको आधारशिला हो। जहा सुशासनको अभाव हुन्छ त्यहाँ दिगो विकास र राष्ट्रिय सुरक्षा लक्ष्य हासिल गर्न कठिन हुन्छ। प्राय: सबै विकासोन्मुख देशहरुमा सुशासनको अभाव रहेको हुन्छ र कानूनको शासन स्थापित हुन सकेको हुँदैन। भएका संस्थागत व्यवस्थाहरु कमजोर छन्। सरकारमा जनताप्रतिको उत्तरदायित्वको अभाव छ। विकास र सुरक्षाको सवालमा जनसहभागिता जुट्न सकिरहेको छैन्। राज्य सन्चालनको प्राय: सबै निकायमा अनुशासनहिनताले जरो गाडेको छ। यस्तो अवस्थामा दिगो विकास र राष्ट्रिय सुरक्षाको उद्देश्य पूरा हुन निकै कठिन पर्दछ।

\section{(च) कुशल कूटनीतिको अभाव}

दिगो विकास र राष्ट्रिय सुरक्षालाई गति दिन बाहिरी प्रभावलाई सन्तुलनमा राख्तुपछ। यसका लागि कुशल कूटनीतिको आवश्यकता पर्दछ। माथि उल्लिखित बुँदाहरुको अवस्थाले गर्दा विकासोन्मुख देशहरुमा कुशल कुटनीतिको विकास हुन सकिरहेको छैन। यसले गर्दा आन्तरिक सुरक्षा कमजोर भएको छ र बाहिरी हस्तक्षेप दिनप्रतिदिन बढ़दै गइरहेको छा यसले पनि थप चुनौती खडा गरेको छ।

\section{(छ) कमजोर नैतिक धरातल}

राज्य सन्चालनका लागि सन्चालकहरुमा उच्च नैतिक चरित्र हुनुपई। यसले राज्य सज्चालनमा धेरै ठूलो भूमिका खेलेको हुन्छ। यसले संचालन तथा जनतामा अधिकार र कर्तव्य दुबैप्रति उत्तरदायी बनाएको हुन्छ। तर तेस्रो विश्वका अधिकांश देशहरुको शासन
व्यवस्थामा कमजोर नैतिक धरातल रहेको छ। यस्तो अवस्थामा दिगो विकास र राष्ट्रिय सुरक्षाका विषयहरु आफैमा चुनौतीपूर्ण रहेको हुन्छ।

दिगो विकास र राष्ट्रिय सुरक्षाको लक्ष्य प्राप्त गर्ने उपाय :

आजको समयमा दिगो विकास र राष्ट्रिय सुरक्षा हासिल गर्ने विषय बहुपक्षीय प्रयासमा आधारित छ। यो एक्लो प्रयासबाट सम्भव छैन्। हरेक देशले आफ्नो परिवेशअनुसार तत्कालीन संविधानलाई लक्षित गरेर विकास नीति र योजना बनाई दिगो विकास र राष्ट्रिय सुरक्षाका लागि अग्रसर हुनुपई। यति मात्र नभएर एक देशको प्रयासलाई साधन र प्रविधिले युक्त अर्को देशले बिना सर्त सहयोग दिने परिपाटीको विकास पनि आवश्यक छ। राष्ट्रिय अग्रसरतामा बहुपक्षीय सहयोगका आधारमा प्रयासरत रहे दिगो विकास र राष्ट्रिय सुरक्षाको लक्ष्य प्राप्त गर्न सकिन्छ। यसका लागि अवलम्बन गर्नु पर्ने केही उपायहरु देहाय बमोजिम रहेका छन् :

\section{(क) प्राकृतिक स्रोत साधनको संरक्षण तथा समुचित प्रयो} ग गर्ने

दिगो विकास र राष्ट्रिय सुरक्षाको अवधारणा नै प्राकृतिक स्रोत-साधनको संरक्षण र सम्बर्द्धन गर्ने, वातावरण प्रदूषण हुन नदिने र आर्थिक विकास गर्दा उपर्युक्त विषयमा ध्यान दिने सर्तमा भएको हो। दिगो विकास र राष्ट्रिय सुरक्षा हासिल गर्नका लागि प्राकृतिक स्रोत-साधनको संरक्षण उच्च सतर्कता अंगाल्दै कटिवद्ध भएर लाग्नु आवश्क छ। यसका साथै नीतिगत स्पष्टता, संस्थागत प्रभावकारिता र कानुनी सक्रियता पनि आवश्यक क।

\section{(ख) वातावरणीय गुणस्तर कायम गर्ने}

दिगो विकासका लागि मुख्यतः जल, थल, वायु र ध्वनि प्रदूषणबाट पृथ्वीलाई मुक्त राख्नु अति आवश्यक छ। धेरै प्रयासका अतिरिक्त यस क्षेत्रमा सोचे जस्तो सफलता हासिल हुन सकेको छैन । यसका लागि मूलतः नीतिगत, संस्थागत र कानुनी व्यवस्था र त्यसको प्रभावकारी कायान्वयन हुनु पछ। 


\section{(ग) दिगो आर्थिक विकास गर्ने}

दिगो आर्थिक विकासका माध्यमबाट देशको समग्र विकास र राष्ट्रिय सुरक्षामा टेवा पुग्ने हुँदा यससम्बन्धी स्पष्ट नीति र त्यसको इमान्दारीपूर्वक कार्यान्वयन गर्नु आवश्यक छ। यसका लागि सर्वसाधारण बिच आयआर्जन र रोजगारीका प्रशस्त अवसरहरु सिर्जना हुनुपछ। कृषि, वन, उद्योग र वलस्रोतको विकासमा जोड दिनु आवश्यक छ। सेवा क्षेत्रहरु पर्यटन, सन्चार र सूचना प्रविधि, वित्त तथा घरजग्गा, निर्माण र यातायातको विकासमा ध्यान दिनुपछ। निजी क्षेत्र र सरकारी निकाय बिच सहकार्य र समन्वय गरी सामाजिक विकासमा लगानी वृद्धि गर्नु आवश्यक छ। यी सबै विकासहरु आफनो देशका माटो, र हावापानी सुहाउादो हुनु पई। आफ्नै देशको विज्ञबाट अध्ययन अनुसन्धान गरी विकासका योजना र सुरक्षा नीति बनाउनुपई। अन्तर्राष्ट्रिय गैरसकारी संघसंस्थाको स्वार्थपूर्ण निर्देशनअनुसार कदापि अगाडि बढ्नु हुँदैन ।

(घ) सामाजिक समानता, समता र सदभाव कायम गर्ने समाजमा कुनै पनि किसिमको विभेद र दून्द्ध भएमा देशको समुच्चा विकास र सुरक्षामा नकारात्मक प्रभाव पर्दछ। त्यसकारण सामाजिक, धार्मिक र साँस्कृतिक विविधताका बिच एकता कायम गर्ने सामाजिक समानता, समता र सदभावको वातावरण हुनु आवश्यक छ। विभिन्न किसिमका विभेदको अन्त्य हुनु आवश्यक छ। यसका लागि सामाजिक सुधार, समावेशीकरण, लैंगिक मलप्रवाहीकरण, पछि परेका र पारिएका वर्ग र क्षेत्रको विकास र सहभागितामा विशेष प्रयास आवश्यक छ।

\section{(ङ) राजनैतिक सहभागिता बढाउनुपर्ने}

देशको समग्र विकास र सुरक्षामा जनताको समुचित सहभागिताको महत्व रहेको कुरो विश्व इतिहासले स्पष्ट गरेको छ। आफनो विकास र सुरक्षाका लागि जनता आफै सहभागी भई सम्पन्न गरेका कामहरु दिगो हुनुका साथै उपलब्धिमूलक भएको पाइन्छ। यसका लागि राजनैतिक रुपमा प्रजातान्त्रीकरण अति आवश्यक छ। अपवाद बाहेक प्रजातात्त्रिक पद्धति भएका देशहरुले
मात्र दिगो विकास र राष्ट्रिय सुरक्षाको लक्ष्य हासिल गर्न सकेका छन् ।

\section{(च) गरिबी निवारणमा जोड दिने}

गरिबीको रेखामुनि रहेका नागरिकले दिगो विकास र राष्ट्रिय सुरक्षाको महत्वलाई बुक्कन सक्दैनन्। बुकिहाले पनि बाध्यतावश यसका लागि योगदान गर्न सक्दैनन् । साँक-बिहानको छाक टार्ने समस्या रहेको नागरिकले न त प्राकृतिक स्रोत-साधनको सावधानीपूर्वक प्रयोग गर्न सक्छ, न त वातावरणमा ह्रास आउन नदिने गरी विकास कार्यमा सहभागी हुन सक्छ। त्यसैले यसका लागि सकेसम्म छिटो गरिबीको अवस्थाबाट नागरिकलाई छुटकारा दिनु आवश्यक हुन्छ। दिगो विकास र राष्ट्रिय सुरक्षा तथा गरिबी निवारण एक अर्काका परिपूरक समेत भएकाले यी दुवै रणनीतिलाई एकीकृत रुपमा अगाडि बढाउनुपछ।

\section{(छ) सुशासनमा जोड दिने}

देशको समग्र विकास र सुरक्षा सुशासनमा आधारित हुन्छ। सुशासनका लागि राजनैतिक व्यक्तिहरुको भाषण र कागजमा सीमित नीति र कार्यक्रमले मात्र सम्भव हुँदैन । प्रजातात्त्रिक र पारदर्शी शासन प्रणालीको अवलम्बन, कानुनको शासन, जनसहभागितामूलक विकास प्रक्रिया, जनताप्रति उत्तरदायी सरकार र प्रशासनिक व्यवस्था, जनताका आधारभूत मानव अधिकारको प्रत्याभूति र राज्य सज्चालनमा स्वच्छता कायम गर्ने राजनैतिक र प्रशासनिक प्रतिबद्धताले मात्र सुशासन कायम हुन सक्छ। सुशासन कायम हुन सके मात्र दिगो विकास र राष्ट्रिय सुरक्षा लगायत राष्ट्रको समग्र लक्ष्य पूरा हुन सक्छ।

\section{निष्कर्ष}

दिगो विकास र राष्ट्रिय सुरक्षा एक सिक्काका दुई पाटा हुन। यी दुवै अवधारणा विकास र वतावरणका बिचको सम्बन्धका आधारमा अगाडि सारिएको हो। देशको राजनैतिक, सामाजिक, सांस्कृतिक, नैतिक र मानवीय पक्षको सामुहिक विकासबिना दिगो विकास र राष्ट्रिय सुरक्षाको लक्ष्य हासिल हुन सक्दैन। यी 
दुबै एकल प्रयासले मात्र सम्भव पनि हुँदैन। यसका लागि राष्ट्रिय तथा अन्तर्राष्ट्रिय स्तरबाट सामूहिक प्रयास हुनु अतिआवश्यक छ। दिगो विकास र राष्ट्रिय सुरक्षाका लागि जनचेतनामा अभिवृद्धि, सैनिक-नागरिक सम्बन्धमा विस्तार, निजी तथा नागरिक सामाजका संस्थाहरु लगायत अन्तर्राष्ट्रिय संघसंस्गाहरुको सहकार्य बढाउनु पनि त्यति नै आवश्यक देखिन्छ। यी सबैको सामूहिक प्रयासलाई प्रतिबद्धताका साथ कार्यान्वयनमा ल्याउनुपई ।

\section{सन्दर्भ-सामग्री}

अधिकारी, बमबहादुर (२०७४). आधुनिक नेपाल राष्ट्रका निर्माता पृथ्वी नारायण शाह काठमाडौं : डिकुरा पब्लिकेसन ।

अधिकारी, सुजन (२०७६) राष्ट्रिय सुरक्ष र विकास: आधार तथा दृष्टिकोणहरु, युनिटी जर्नल-१, पृ. २२७-३२१

आचार्य, बाबुराम र योगी नरहरिनाथ(सम्पा.)(२०७४). बडामहाराजधिकाराज श्री $y$ पृथ्वीनारायण शाहको दिव्य उपदेश: फाइनप्रिन्ट बुक्स

केन्द्रीय तथ्याड़क विभाग (२०६५) गणक निर्देशिका, काठमाडौं : केन्द्रीय तथ्याङ विभाग.

खरेलोपाध्याय, पदमभक्त(२०७६) राष्ट्रिय सुरक्षा र विकास: एक रथका दुई पांग्रा-युनिटी जर्नल-१, पृ. १९१-९ूू गौतम, असफल(२०७६) राष्ट्रिय सुरक्षामा विकासको पार्श्वचित्र . युनिटी जर्नल-१ पृ. १४२-पू ७१

चुङ चाड, (२००४) नेपालको राष्ट्रिय सुरक्षात्मक रणनीति तथा नेपाल-चीन सम्बन्ध, काठमाडौं- चीन अध्ययन केन्द्र ।

जौहरी, जे.सी/सीमा (२०००) अन्तर्राष्ट्रिय राजनीति, मेरठ : राजीव प्रकाश

त्रिताल, शारदाप्रसाद (२०६२) दिगो विकास : अवधारणा, विद्यमान स्थिति र भावी दिशा. प्रशासन, वर्ष ३६, अंक, पूर्णाड्क १००.पृ.
नेपाल सरकार नेपालको संविधान (२०७२) कानून किताब व्यवस्था समिति

नेपाल सरकार पन्ध्रौं योजना (२०७६) राष्ट्रिय योजना आयोग, सिंहदरबार काठमाडौं.

नेपाल सरकार (२०७३) सुरक्षानीति नेपाल कानून आयोग नेपाल सरकार (२०७२) सूचना विभाग नेपाल परिचय. काठमाण्डौ : सुचना विभाग

बंग, के.आर.(२०१०) विकास प्रशासन : महाराष्ट्र, बिद्या बुक्स

बन्जाडे, शर्मिला (२०१९) राष्ट्रिय सुरक्षा व्यवस्थापन : अवधारणा, क्षेत्र र नेपालमा राष्ट्रिय सुरक्षाका विद्यमान

प्रावधानहरु. प्रशासन

बस्त्यात, रामसिंह (२०७४) राष्ट्रिय सुरक्षाका आधार र चुनौती सिपाही $y q / y$, पृ. प३३-पू६

शर्मा, कमलराज.(२०६६) सोसिएल इन्ट्टिच्यूसन्स् एन्ड प्रोसेजेज सोसिओलोजिकल एन्ड एन्थ्रोपोलिजकल एनलाइसिस् काठमाडौं : ग्लोबल पब्लिकेसन प्रा.लि.।

World Bank. (2003) World Development Report: Sustainable Development in A Dynamic World,

Transforming Institutions, Growth and Qualiity of Life: World Bank.

UNDP. (2020). Human development Report 2020. The united national development program, new plaza,

Newyork NT1007 USA. 


\section{Contributors}

Anand Sing Bhat, Former Colonel of Nepali Army

Ashutosh Pandey, Student, National Law Collage, Sanepa Lalitpur

Bharat Khanal, Section Officer, Ministry of Foreign Affairs, Nepal

Bikash Gyawali, Student, Masters Public Administration, Tribhuvan University

Bishnu Prasad Acharya, Section Officer, Ministry of Home Affairs

Dharma Bahadur Baniya, Former Brigadier General of Nepali Army

Divesh Barsing Thapa, Student, Nepal Commerce Campus, Management Faculty

Dr. Eak Prasad Duwadi, Assistant Professor, Kathmandu University

Gaurav Bhattarai, International Relations Scholar and the faculty in the Department of International Relations and Diplomacy (DIRD, Tribhuvan University. Associated with the Nepali Military Academy, Kharipati as a faculty of Strategic Studies

Dr. Ishwari Bhattarai, Lecturer at Thames International College, Kathmandu

Hansawati Kurmi, Researcher and Writer, Pragya pratisthan

Indira Sharma, District Judge, Jhapa District Court

Dr. Jhamak Prasad Sharma, Retired Joint Secretary, Ministry of Law

Kamal Bahadur Mahat, Employment Coordinator, Salyan

Dr. Keshav Bashyal, Department of International Relation and Diplomacy, Tribhuvan University

Laxmi Bilas Koirala, Former Joint Secretary of Nepal

Dr. Laxmi Dhungel, Kathmandu University, School of Art, Visiting Faculty

Man Bahadur Karki, Former Pilot Lieutenant Colonel of Nepali Army 
Manish Raj Aryal, Graduate Engineer, Pulchowk Campus

Nagendra Bahadur Bhandari, Lecturer, Prithvi Narayan Campus, Pokhara

Padam Kumar Angbo, Former Brigadier General of Nepali Army

Phanindra Subba, Teacher, Strategic Studies at Nepali Military Academy, Kharipati

Ramesh Aryal Under Secretary, Ministry of Finance

Ramesh Raj Paudel, Account Officer, PEFA Secretariat

Sachin Dahal, Industrial Engineer, Nepal Science and Technology Research Center

Sambid Bilas Pant, Freelance Writer and Copy Editor

Sasmita Gautam, Pmamp Lee Intern, Rajapur Bardiya

Sirjana Pun, Student, University of Cincinnati, Ohio, USA

Sumitra Karki, Research Associate, Nepal Institute for International Cooperation and Engagement

Susma Giri, Section Officer, High Court Patan 